\title{
Judíos y mudéjares en la Catedral de Segovia (1458-1502)
}

\author{
MARÍA LÓPEZ DíEZ \\ Doctora en Historia del Arte (Universidad Autónoma de Madrid)
}

\section{RESUMEN ABSTRACT}

Este trabajo pretende destacar y analizar la activa participación de mudéjares y judios en la arquitectura de los templos cristianos a fines de la Edad Media. El punto de partida de esta investigación son las fuentes documentales de la catedral de Segovia durante la segunda mitad del siglo xv. A través de este ejemplo, se trata de establecer una aproximación a los términos en los que se lleva a cabo la implicación de las minorias en estos procesos constructivos.

\section{PALABRAS CLAVE}

Arquitectura, Siglo xv, Catedral, Segovia, Judíos, Mudéjares, Enrique IV, Reyes

Católicos.
The aim of this article is to analyse the participation of Jews and "mudejares" in the construction of Christian temples at the end of the Middle Ages in the Iberian Peninsula. The documentary sources of Segovia's Cathedral during the second half of the fifteen century have been the starting point of this investigation. Therefore, Segovia's archive can be understood as a case study that allows us to value the participation of religious minorities in this process.

\section{KEY WORDS}

Architecture, 15th Century, Cathedral, Segovia, Jews, Mudejar, Henry Ivth, Catholics Kings.

El proyecto arquitectónico más ambicioso de los centros urbanos durante el Medievo fue, sin duda, la construcción de catedrales. La complejidad de estos edificios exigía una extraordinaria movilización de medios económicos y humanos. Por esta razón, no es de extrañar que, aun siendo la catedral fortaleza de la fe católica, también se involucraran en esta empresa judíos y mudéjares, tanto en la ejecución como en algunos aspectos de la financiación. Segovia, con una de las aljamas más potentes de Castilla, es un buen exponente para valorar la implicación de las otras religiones en la edificación de iglesias cristianas a fines de la Edad Media. 
Antes de abordar cualquier estudio que afecte a la catedral de Segovia, hay que tener en cuenta la particularidad que presenta por ser el único caso de CastiIla en el que la sede medieval no ha permanecido. Iniciada en el siglo x\| y fortificada como la de Ávila, la catedral de Santa María la Mayor, con todos sus edificios anejos estaba situada frente al Alcázar. Esta estrecha vecindad suponía una frecuente fuente de conflictos entre ambas fortalezas que, en muchas ocasiones, desembocaban en luchas armadas. La confrontación definitiva tuvo lugar durante el levantamiento comunero (1520), cuando los sublevados se encastillaron en la catedral, causando incontables destrozos que propiciarían el traslado de la iglesia a la plaza mayor de la ciudad.

Prácticamente, no se conoce ninguna característica del templo románico. Apenas existen vagas referencias sobre la distribución de la planta y es sabido que los materiales predominantes en la construcción eran mamposteria, ladrillo y, en algunas partes, tapial. La debilidad del sistema constructivo provoca que la iglesia llegara al siglo XV con graves deterioros en su fábrica e, incluso, con un claustro que amenazaba ruina. El mal estado obliga a la mesa capitular a plantear una serie de actuaciones para subsanarlo y se emprende un complejo programa de iniciativas que tendrán como resultado la transformación del edificio catedralicio. Estas medidas se entienden desde una perspectiva global y, por tanto, no se ciñen unicamente a las intervenciones arquitectónicas, sino que también se acompañarán de la adquisición y dotación de elementos indispensables para la iglesia como son retablos, altares, objetos de culto, ropas litúrgicas, etc. Para llevar a cabo este proyecto, es fundamental el impulso que otorgan el rey Enrique IV (1454-1474), continuado por Isabel I (1474-1504), y el obispo Juan Arias de Ávila (1461-1497) y sus sucesores.

La implicación de estos personajes está sobradamente justificada puesto que la corona y la iglesia son los principales promotores artísticos de este periodo. Además, Enrique IV distingue a Segovia con una especial predilección que le lleva a favorecer y promover numerosos edificios religiosos y civiles en la ciudad, como Santa María del Parral, San Antonio el Real, el palacio de San Martín o el Alcázar. Por su parte, la figura del prelado Arias de Ávila, hijo del tan influyente Diego Arias, contador real de origen converso, se inscribe dentro de los círculos humanistas de su tiempo. Su preocupación por la cultura se traduce en las muchas decisiones que adopta para mejorar la formación e instrucción del clero y, sobre todo, en que a él es atribuida la implantación de la primera imprenta en la Península ${ }^{1}$.

1 La bibliografía sobre este personaje es abundante. Entre los estudios específicos más relevantes destacan: Álvarez, P., Pedrarias Dávila. Contribución al estudio de la figura del Gran Justador gobernador de Castilla del Oro y de Nicaragua, Madrid, 1944; LE FLEM, J. P., "La première version castillane du testament de don Juan Arias Dávila evêque de Segovie", en Estudios Segovianos, XXII, 1970, págs. 1746; Cantera Burgos, F., Pedrarias Dávila y Cota, capitán general y gobernador de Castilla del Oro y Nicaragua: sus antecedentes judíos, Madrid, 1971; CARRETE, E., Proceso inquisitorial contra los Arias Dávila segovianos: un enfrentamiento social entre judios y conversos, Salamanca, 1986; CONTRERAS, M. ${ }^{a}$ E., "Diego Arias de Ávila en la tradición y en la historia", en Anuario de Estudios Medievales, n. "15, 1985, págs. 475-495; AzCONA, T., "Juan Arias Dávila» en ALDE, Q. MARiN, T. y VIVES, J. (dir.), Suplemento 
Sin embargo, el decidido respaldo del rey y del obispo no es suficiente para hacer frente a la ingente inversión que exigían estas actuaciones. También es necesario recurrir a todas las fuentes de financiación disponibles: desde los recursos propios de la diócesis hasta el Papado de Roma, desde el estamento nobiliario a la ciudadanía. Incluso, a veces, a falta de capital, el cabildo se ve apremiado a solicitar préstamos avanzados por judios. Si la cooperación económica no suponía ningún acto extraordinario, menos aún el trabajo que dempeñaban, estos y los mudéjares, como artífices en las obras catedralicias. En estos años, existe en la Catedral de Segovia una amplia relación de profesionales pertenecientes a las minorías que trabajan en calidad de alarifes, carpinteros, enlucidores, herreros, sastres, encuadernadores... Una larga lista que, a raíz de los decretos de 1492 y 1502 , se verá bruscamente sesgada o transformada por las conversiones.

\section{FINANCIACIÓN JUDIÁA Y OTRAS ACTIVIDADES}

Uno de los aspectos más destacados de la participación judía en la catedral de Segovia es lo que atañe al aporte económico que realizan mediante préstamos. La importancia de la financiación judia queda patente a través de las cuentas de la mayordomía de la Fábrica, principal fuente documental de esta investigación, relativas a 1473. En este año, el dinero recibido de miembros de la aljama asciende a más de 13.000 maravedies, dinero destinado a sufragar los gastos ocasionados por la construcción del nuevo claustro. Juan de Cuéllar, canónigo beneficiado y mayordomo del Común, Pitanzas y Horas, tiene que pagar diversas sumas al mayordomo de la Fábrica, Pero Alonso, que son adelantadas por Rabí Abraham Cohen, Rabi Semaya, Ismael Abenforma y Abraham Molho ${ }^{2}$. También en otros momentos

del Diccionario de Historia Eclesiástica de España, Madrid, 1987; Rabade Obradó, M. P., "La religiosidad de una familia conversa a finales de la Edad Media: Juan Arias Dávila", Ciencias humanas y sociedad, (Madrid, 1993), págs. 225-234; EDwARDS, J., «Bishop Juan Arias de Ávila of Segovia: judaizer or reformer?", en Religion and Society in Spain 1492, Andershot, 1996, págs. 71-86; Galindo, A. (ed.), Arias Dávila: Obispo y Mecenas. Segovia en el siglo xv, Biblioteca Salmanticensis 197, Salamanca, 1998.

2 Archivo Catedral de Segovia (A.C.Sg.) Libro de Fábrica, C-202. 4-III-1473: "En quatro dias del mes de março reçeby del dicho Juan de Cuellar myll e nueveçientos e ochenta mrs los quales delante del dicho Juan de Cuellar me dio don Ismael Abentorna por raby Habraham Cohen dentro en mi casa que le devya Juan de Cuellar»

11-1II-1473: «Este dicho dia reçeby mas del dicho Juan de Cuellar tress miyll mrs los quales me dio un judio en casa de Abraham Molho delante el dicho Juan de Cuellar para en pago de los quales dichos tres myll mrs me dio el dicho judio veynte e çinco reales e en prendas de los otros mrs restantes me dexo una taça de plata que puso un marco menos tress reales e una sortija de oro de florines que puso tres florines e medio quedaron estas dichas prendas en dos myll e dosçientos e çinquenta mrs que fasen los dichos tress myll mrs con los dichos veynte e çinco reales"

14-V1-1473: «Reçeby mas del dicho Juan de Cuellar quatro myll e tresyentos e dies mrs los quales me dio por el en diversas veses Raby Abraham Cohen judio segund fisimos todos en la claustra cuenta

Reçeby mas del dicho Juan de Cuellar dos myll e quynientos mrs los quales reçeby en esta manera los myll e seisçientos mrs de Juan de Castro por mandado de raby Semaya judio e los nueveçientos reçeby del dicho Juan de Cuellar vispera de sant Pedro los quales dio el dicho judio en treynta reales a Juan de Cuellar para my son todos dos myll e quynientos mrs estos ii M D son de un conosimyento que el dicho judio dio a Juan de Cuellar e Juan de Cuellar me dio a my e le di al judio 
se vuelve a tener constancia de esta práctica financiera, puesto que, en las cuentas de 1489, el mayordomo de la Fábrica cobra parte de sus atrasos gracias al dinero que proporciona Semaya Meme:

"Tome yo para en parte de pago de mi salario que los señores me mandaron por los seys años pasados a çinco myll mrs cada año tome quinse myll y çiento y çinco mrs que me libro Pero Alonso en Semaya Meme los dose myll de los rediesmos del arçediano y tres myll y çiento y çinco de la plata xvMcv» 3 .

Las referencias que encontramos de estas personas son escasas. Rabi Abraham Cohen, hijo de Rabiça (rabí Isaac) Cohen, vivía con su mujer, Doña Paloma, en unas casas de la Aljama. En 1494 consta que estaban sin habitar, lo que indica que probablemente abandonaron la ciudad tras el edicto de 1492. En diversas noticias se habla de Rabí Abraham «físico, cojo judio» que, en principio, se podría identificar con Abraham Cohen. Sin embargo, dado que la mayoría de las informaciones proceden de censos, no coinciden las casas del físico con las de Rabí Abraham Cohen, por lo que se puede considerar que se trata de personas distintas ${ }^{4}$.

Respecto a Rabí Semaya, existen más noticias si admitimos que se trata del físico o médico de Enrique IV. Los datos se fechan de 1456 a 1469 con menciones a Samaya Lubel, vecino de Segovia, rabí y juez mayor de todas las aljamas de judios $^{5}$. Sin embargo, la mención a Semaya Meme de 1489 arroja nuevas dudas sobre la identidad de estos personajes, puesto que no se puede establecer con seguridad si Rabi Semaya es Semaya Meme o se trata de dos individuos distintos. En cuanto a Ismael Abenforma, aunque en estos años se menciona a varias personas con este apellido, ninguno responde a Ismael. Si que existe un maestre Abenforma del que no se puede precisar con certeza que corresponda al que aqui nos ocupa ${ }^{6}$. Por último, Abraham Molho, de Aguilafuente, consta en la relación de judíos que se suman al empréstito a la Hacienda Regia de 1483. También puede que sea el mismo que menciona el Libro de Acuerdos Catedralicios, haciendo referencia a su mujer Ursol ${ }^{7}$.

En cuanto a la actividad laboral de los judíos en las obras, existe una marcada tendencia a que sean los que se ocupen de la confección y reparación de ropas li-

Reçeby mas por Juan de Cuellar del dicho Semaya judio mill e quatroçientos mrs los quales me dio estando çenando en tress doblas a treynta e vii enriques en quatroçientos e dos mrs que monto en todos los dichos myll e quatroçientos mrs"

19-VII-1473: «Reçeby de Symaya judio çient mrs"

3 A.C.Sg. Libro de Fábrica C-206. 21-XII-1489.

${ }^{4}$ La información proveniente de Libros de Censos, Acuerdos y Pitanzas de la Catedral de Segovia aparece recogida en RUIz HERNANDO, J. A., El barrio de la Aljama hebrea de la ciudad de Segovia, Segovia, 1980, págs. 33. (21-III-1475), 36 (10-X|I-1481) y 41 (20-V|I-1494).

5 BAER, F., Die Juden im christlichen spanien. Erster teil Urkunden und Regesten (1929-1936). Gregg International publishers limited, England, 1970, pág. 321; AzconA, T. de, Isabel la Católica. Estudio crítico de su vida y su reinado, Madrid, 1993, pág. 321

6 Ruiz, A. El barrio de..., pág. 37 (26-III-1490 y 11-Vl-1490); pág. 70 (1494).

7 LADERO QUESADA, M. A., "Un préstamo de los judíos de Segovia y Ávila para la guerra de Granada, en el año 1483", Sefarad 35:1/2, 1975, pág. 155; RuIz, A. El barrio de..., pág.41, 24-XI-1493. 
túrgicas, encuadernación, relojería y herrería o forja. En estos años, dentro del programa de renovación del templo, se adquieren gran número de vestidos y telas para el culto y se reciben importantes donaciones, muchas de ellas debidas a la generosidad de Enrique IV, Juan Arias de Ávila u otras figuras conocidas. Por otra parte, conviene recordar la importancia de las telas como eficaz vehículo en la transmisión de repertorios decorativos. La facilidad de transporte y el amplio mercado que existia favorecen los intercambios ornamentales, que se distribuyen con una agilidad mayor que otras expresiones artísticas. Por esta razón, las casullas, dalmáticas o capas pluviales de estos años, anticipan la incipiente estética renacentista antes que la arquitectura o la escultura.

Es de sobra conocido la preeminencia de los mudéjares en el ámbito textil durante el siglo $\mathrm{XV}^{8}$. Como se puede comprobar mediante la información que nos proporciona el archivo catedralicio, la mayoría de los paños, brocados y telas, en general, eran de manufactura mudéjar. No obstante, en la Catedral de Segovia, la ejecución y reparación de gran parte de las vestiduras litúrgicas se encarga a judíos y no a mudéjares. En los libros de Fábrica relativos a la década de los 60 , se menciona a Alonso brocador, cristiano, y a una serie de judíos que, por no especificarse el nombre, no se puede precisar su número, puesto que solo se alude a su religión.

Sólo se menciona expresamente a Meme y a su hijo, del mismo nombre, en 1478. Puede tratarse de Semaya Meme, citado anteriormente, o que se refiera a Meme el Viejo o Abraham Merne. De este último tenemos noticias procedentes de 1483, ya que aparece en la relación de préstamos judíos para la Guerra de Granada. También en 1488 y 1498, cuando bautizado con el nombre de Fernán Gómez, es acusado de judaizante ${ }^{9}$ :

"Conpre de casa de la mora (sic) de Meme para enforrar dos capas que se fisyeron para maytines con las otras dos que abyamos fecho dies e ocho varas de lyenço asul a veynte e seys mrs la vara que montan cccclxviii sobraron tres varas

Conpre de la dicha judia para flocaduras en el pavellon que se fiso y cordones y borlas de tres colores dos honças menos quarta de seda a çiento la honça que montan clxxv"

"Pague al judyo que fase las vestimentas poque desfiso la capa de los pavones y la torno a faser e guarneçyo la çenefa de lienço asul para las manos Ix

De lienço asul que tomo de casa de la de Meme el moço para la guarneçer lii» ${ }^{10}$

Después de 1492, se ocupan de las ropas litúrgicas Diego y García Rosa, sobre los que no hay ningún dato para pensar que se pueda tratar de judíos bautizados ${ }^{11}$.

${ }^{8}$ Echevarria Arsuaga, A., La minoria islámica de los reinos cristianos medievales. Moros, sarracenos, mudéjares, Málaga, 2004, págs. 104-105.

9 Ladero Quesada, M. A., "Un préstamo...", pág. 155; Baer, F., Op. Cit., págs. 520 y 526.

10 A.C.Sg. C-203. $3^{\text {a }}$ Semana-V-1478; 2. Semana-VIII-1478.

1 A.C.Sg. Libro de Fabrica, C-208, en 1495 se menciona a Diego cordonero; Libro de Fabrica, C210, en 1496, a Garcia Rosa. 
La mayoría de estos trabajos realizados por judíos consisten en la reparación o transformación de ropas, en muchos casos, reaprovechando telas y viejas vestiduras. Entre el año 64 y 83, destaca el número de casullas, que superan las doce, una de ellas confeccionada a partir de una seda morisca, donada por Diego Arias; dos manipulos; tres albas con guarniciones de seda leonada; un frontal amarillo de chamelote o pelo de camello; un pabellón con cintas moriscas anchas, con hilo de oro y adornado con cordones y borlas de tres colores, y más de doce capas. Las capas resultan las vestiduras más vistosas, dada su utilización en fiestas litúrgicas y ocasiones especiales. Buen ejemplo de ello son seis capas coloradas, aderezadas con cenefas, donación del rey Enrique IV; otra capa roja, brocada a base de círculos o "labores redondas", adornada con una cenefa rica y una capa verde en raso, lienzo azul e hilo de seda, que se decora con unas imágenes coronadas, seguramente santos $^{12}$.

La encuadernación es otro aspecto en el que sobresale la contribución de los artífices judíos a la catedral segoviana. Al igual que en el capítulo textil, de nuevo encontramos a judíos responsabilizándose de la encuadernación de libros, oficio tradicionalmente asociado a la artesanía mudéjar ${ }^{13}$. El aumento de la libreria fue muy importante a finales del siglo xv. A ello contribuye, sin duda, la introducción de la imprenta en los primeros años de la década de los $70 \mathrm{y}$, desde luego, el especial interés con que el obispo Juan Arias de Ávila se preocupó de la educación y cultura del clero secular, comenzando por la mesa capitular. De hecho, son abundantes los ejemplares, entre manuscritos e incunables, que se conservan en el archivo catedralicio marcados con el ex libris del prelado, procedentes de su biblioteca personal:

"Otrosy dio a la dicha yglesia de segovia todos y cualesquier libros en las [partes] de españa queriendo como quiso y ansimismo mando so la dicha pena de excomunion trina canonica monicione premissa que ninguno los pueda vender ni vendan troquen ni enpeñen ni los saquen fuera de la dicha yglia sin expresa licencia y facultad del obispo que por tiempo fuere" ${ }^{14}$.

Así observamos que, coincidiendo con su episcopado, el número de libros en la catedral se incrementa notablemente y, quizá, por esta razón, el cabildo acuerda hacer una nueva librería en 1504, encargando las trazas a Juan Gil de Hontañón. Aunque muchos son de factura local - hasta el punto de que se ha hablado de un taller propio de la Catedral-, también se recurre a los mercados bibliográficos más frecuentados de estos años: Medina del Campo, Burgos, Ve-

12 Algunos ejemplos en A.C.Sg. Libro de Fábrica C-201, 5-XII-1464; 5-IV-1465; II-1466. Libro de Fa-

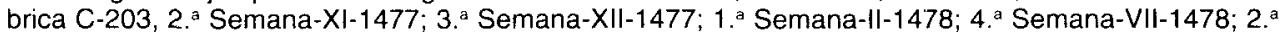
Semana-VIII-1478. Libro de Fábrica C-204, 3. ${ }^{\circ}$ Semana-V-1479. Libro de Fábrica C-206, 24-VII-1483

${ }_{13}$ No obstante, cada vez se abunda más en la aportación de los judios a las llamadas encuadernaciones mudéjares, vide Rodriguez DiAz, E. E., "La industria del libro manuscrito en Castilla: Fabricantes y vendedores de pergamino (ss. XII-XV)". Historia, Instituciones, Documentos, 28, 2001, págs. 313-351.

14 Le Flem, J. P., Op. Cit., pág. 41. Sobre la biblioteca en estas fechas, cfr. Valverde del BarRio, C., Catálogo de incunables y libros raros de la S.l. Catedral de Segovia, Segovia, 1930. 
necia, etc. ${ }^{15}$. Sin embargo, además de la realización de nuevos volúmenes, se detecta un creciente interés por encuadernar los ya existentes. La mayor parte de las veces, las reencuadernaciones obedecen a razones de estricta necesidad pero, también, indican una nueva sensibilidad hacia el libro como objeto. Esto explica el desarrollo de los gofrados que alcanzan un gran valor estético con diseños tan similares, en composición, a los que ofrecen los artesonados y carpinterias de armar.

Un ejemplo sobresaliente por su importancia bibliográfica es la referencia que encontramos del "santoral (sic) de Aguylafuente", que no puede ser otro que el célebre Sinodal de Aguilafuente. El ejemplar, considerado el primer incunable castellano, fue ordenado por Juan Arias de Ávila e impreso por Juan Parix en 1472 , con motivo del Sínodo que tuvo lugar en la localidad segoviana. Los libros de Fábrica mencionan a judíos, aunque únicamente se da el nombre de Raby librero, pero también a cristianos dedicados a esta materia. Contra todo pronóstico, no existe ninguna alusión a encuadernadores mudéjares, lo que pone en duda la aceptada hegemonía de la comunidad mudéjar en esta materia:

"Conpre para cubrir e guarneçer çiertos libros en el coro quatroçientas tachuelas a syete mrs. e medio el çiento que montan $x x x$ fisolas un judyo que bive al canton de sant Çebrian a la puerta del corral",

«Pague mas por enquadernar el dicho libro (un responsorio) al judio Raby librero e le cobrir Xc"

«En trese de abril di al dicho judio encuadernador por seys libros que encuaderno convyene saber un dominycal que comiença dia de la Resurreçion et el santoral de Aguylafuente et un responsorio que comiença de Santa Marya de las Nyeves et otro responsorio que comiença en labronte e un salterio grande de los façistoles et las tablas veynte un reales en que se montaron dcli a tres reales e medio por cada libro" ${ }^{16}$.

Es en el trabajo de forja o herrería donde la labor de los judíos es predominante ya que, según la información catedralicia, parece ser un oficio desempeñado por individuos de esta comunidad, prácticamente sin excepción, Así, desde los primeros años registrados en los libros de Fábrica, vemos como el trabajo de forja es ejercido por judíos regularmente ${ }^{17}$. Sin embargo, desde 1478 , la presencia de Yuçe Biton va a ser constante durante cuarenta años como herrero de la iglesia. Esta figura reviste gran interés puesto que permite seguir su trayectoria hasta

15 Ocho Siglos de Encuadernación Española. Bibliotheca Wittockiana, Bruselas, 1985; RUIZ DE ELVIRA, I., "Las encuadernaciones mudéjares de la Catedral de Segovia". XVIII Congreso Internacional de Bibliofilia. (Madrid, 1993); López DiEz, M. ${ }^{a}$ B., "Las artes en el siglo XV: El mecenazgo de los Arias Dávila", en Galindo, A. (ed.), Op. Cit., págs. 287-288.

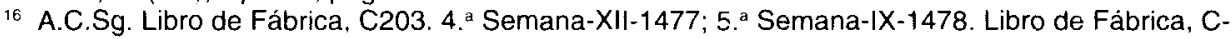
205. 13-IV-1481

17 A.C.Sg. Libro de Fabrica, C-201. 17-VIII-1464: "Costaron unos fierros para el facistol el qual fiso el judio coxo myll mrs".

En 1473 se paga a un judio herrero todos los meses $50 \mathrm{mrs}$. por el cuidado de las herramientas, por ejemplo, Libro de Fábrica C-203. 30-IV-1473: "Pague al judio ferrero çinquenta mrs deste dicho mes de abril por aguçar la ferramyenta de la claustra". También aparecen pagos similares en 1475 y 1477. 
más allá de la conversión, cuando continúe desarrollando su labor con el nombre cristiano de Alonso de Palencia. Además, otros datos ajenos a la mayordomía de la Fábrica completan, a pesar de las evidentes carencias, la aproximación a este personaje.

La primera vez que se cita a Yuçe Biton es en diciembre de 1478. Su trabajo consiste no solo en el mantenimiento de herramientas, cometido por el que cobra cincuenta maravedís al mes, recibidos en tres tercios a lo largo del año, sino que también se hace cargo de la mayor parte de las labores de cerrajería (rejas, bisagras, filacterias, clavazones, etc.). Asiste en la catedral continuadamente hasta su última aparición bajo este nombre, en marzo de 1492, y dos años después, en agosto de 1494, reaparece como Alonso de Palencia, retomando su labor hasta 1519. A partir de 1520 , sólo se menciona a su hijo ${ }^{18}$.

Por suerte, la prueba de su conversión se recoge en los censos procedentes del Archivo de la Catedral de Segovia. En mayo de 1496, queda registrado como Alonso de Palencia acude a la autoridad para hacer efectiva una donación por parte de sus padres. La escritura, redactada en hebreo y que tiene que ser traducida por dos conversos, se fecha en 1486. Por la misma, los padres del antes conocido

18 Por las abundantes alusiones al trabajo de este herrero, a continuación solo transcribiré una se-

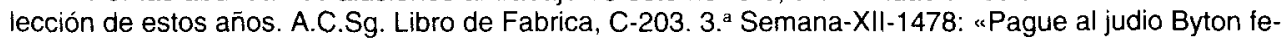
rrero de tres badajos de los esquilones a largo cada dos dedos e de seys clavos rexones para pegar los pedaços y dos grapas de las claves de la segunda capilla junta con la que çerro Gonçalo Rodrigues Ixxv"»

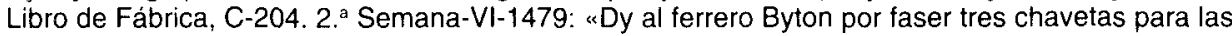
alas de los angeles ix

Costaron adobar syete caras de angeles para el dicho dya (Corpus Christi) tres reales e medio que montan CV»

19-XII-1484: «Pague a Yuçe Byton ferrero de su quitaçion de los dos terçios deste año a çinquenta mrs cada mes porque adobe las ferramyentas de la obra que montan los mrs destos dichos dos terçios que se le devyan deste año quatorse mrs cccc»

Libro de Fábrica, C-205. 23-V-1481: «En xxiii dias de mayo del dicho año de Ixxxi di a Juan Abad para conprar fierro para la puerta del patin de la claustra que son çinquenta e nueve mrs que se montaron en çiento e çinquenta e tres libras de fierro que fueron menester para la dicha puerta e se conpraron a tres $\mathrm{mrs}$ cada libra et mas le dy treynta reales para dar al judio Biton por la fechura de las dichas puertas porque por tanto se convyno con el que se monta en todo myll e tresyentos e ochenta e nueve mrs"

Libro de Fábrica C-206. 24-IX-1487: "Començamos a faser el badajo de la campana mayor de fierro nuevo en las casas de la yglesia que fueron de la obispalia anduvieron Yuçe Byton ferrero Seton Judio obrero y Pilo obrero y Pedro ferrero a Sant Marcos que fase la clavason para la sala que se le quito a Juan de Luna a quarenta mrs y que se mantengan dellos y non querian menos de un real cxx"

25-IX-1487: "Martes seguyente anduvieron en el dicho badajo el dicho Yuçe y el dicho Seton y Pilo a los dichos Seton y Pilo IxxX»

29-XII-1488: “Pague a Yuçe Byton terrero de la dicha iglesia de su quitaçion que le dan cada año dc»

Libro de Fábrica C-208. 20-ll1-1492: "Mas di al dicho Biton por mandado de los deputados por ferramyentas que habia adobado para la iglesia e por cargo que del tenya la fabrica dosçientos mrs"

3-VIII-1494: "Que di mas a Alonso de Palencia ferrero por dos pernos que fiço para las ventanas del cabildo dies mrs."

Libro de Fábrica C-216. 1519: «Di Alonso de Palencia porque adobo un candelero de hierro de aquellos que estan en las gradas del altar y porque adobo un candelero de los facistores de los maytines y asento unos libros dos reales lxv»"

1520: «Pague a su fijo de Alonso de Palencia a xviii de novienbre por doze bisagras para dos armarios que se fizieron en la torre de Santa Clara para poner toda la plata a sesenta mrs por cada una que montan dccxx" 
como Yuçe Biton, Herza Biton y Jamila, le donan unas casas en la Judería ${ }^{19}$. Otras referencias al apellido Biton las encontramos en 1481, donde aparece Rabi Salamon Biton como diputado de la Aljama y en 1510 cuando se menciona expresamente el carácter de converso del herrero Alonso de Palencia, según la relación de censos de la parroquia de San Miguel. Esta última noticia nos cuenta, además, que se casó con Catalina Alonso y que tenía dos hijos, Diego y Fernando, uno de los cuales, casi con toda seguridad, sería el que continuó con el oficio del padre en la Catedral ${ }^{20}$.

Entre sus colaboradores, aparte de su hijo, están Seton y Jaco Pilo que trabajan en 1487 . Existen múltiples referencias a este último nombre relacionadas, sobre todo, con censos de casas. No obstante, abunda el nombre de Pilo puesto que, en estos años, hay varios sujetos así apellidados en la aljama. En mayo de 1492, consta como propietario de unas casas en la plazuela de la Judería. En 16 de mayo de 1492, estos mismos inmuebles son vendidos a Juan García, maestrescuela de la Catedral. Por la escritura de venta, sabemos que el herrero estaba casado con Exçer y era padre de Yuda y Jaco. Se puede deducir que dejaron Segovia en $1492^{21}$.

Muy relacionado con las labores de herrería, en la década de los 60, la Catedral dispone de un relojero llamado Duarte. Este se encarga de los ajustes y puesta en funcionamiento del reloj de la iglesia. También hará unas cerraduras y sus llaves para los órganos y, por la importancia de estos instrumentos, se puede considerar que serían unas piezas más cercanas a la orfebrería que a la forja. EI nombre de Duarte, asociado a un joyero, profesión no demasiado alejada, aparecerá en el registro de judíos conversos de 1510, aunque por la separación entre las fechas, bien pudiera tratarse de un descendiente ${ }^{22}$.

Por último, la presencia judía es indiscutible en el terreno de los batidores de oro y plata. Un elemento de primer orden en toda manifestación artística de este periodo son los panes de oro, mercadería habitualmente gestionada por la comunidad judía. La demanda de este material es habitual en pinturas, esculturas y, muy importante, en la decoración de carpinterías de armar y techumbres, en general. Por ello, la catedral adquiere grandes cantidades de panes de oro, suministrados por los batidores Jaco Anys y Sornaga, que serán empleados en la pintura de la capilla mayor y en la decoración del nuevo cabildo que se hacen en

19 Ruiz, A., La aljama..., págs. 43-45.

20 Rabi Salamon Biton en FITA, F., «La Judería de Segovia. Documentos inéditos» en Estudios históricos. Colección de articulos escritos y publicados por el R P. Fidel Fita en el Boletín de la Real Academia de la Historia, T.VI, Madrid, 1886, pág. 6; Batalllon, M., “Les nouveaux chretiens de Segovie en 1510", Estudios Segovianos, T.X, 1958, pág. 408.

21 Ruiz, A., La aljama..., págs. 35, 38-39, 46-48.

22 A.C.Sg. Libro de Fabrica, C-201.10-1X-1463: " Fue convenydo por el señor chantre con Duarte relojero la mudada del reloj con çiertas cosas que fiso de nuevo tres myll e tresyentos mrs solas sus manos"

17-V-1464: «Costo un çerrojo e çerradura con dos llaves que fiso Duarte para los horganos mayores treynta e seys mrs". Duarte, relojero, casado con Mari Lopez en Batall Lon, M., Op. cit., pág. 409. 
estos años ${ }^{23}$. Jaco Anys puede ser el batidor que actúa como representante de la aljama en $1482^{24}$. Respecto a Sornaga, hay un Yudá Sornaga que en 1481 actúa como veedor de la aljama y, en 1488 , se tiene constancia de Mair Sornaga ${ }^{25}$. Obviamente, no se puede establecer cual de estos es el batidor que provee al templo segoviano.

\section{MAESTROS Y ARTESANOS MUDÉJARES}

Como es bien sabido, la contribución de los mudéjares a la construcción medieval resulta, sin duda, uno de los capítulos más interesantes de la historia de la arquitectura peninsular. Este aspecto debe ser valorado no sólo por la abundancia de artífices, sino por las visiones y técnicas con las que enriquecen el ámbito constructivo, siendo muy importante su aportación en cuanto a la organización del trabajo se refiere. Es más, las primeras ordenanzas y regulaciones públicas que se observan en la arquitectura del medievo son las que competen al oficio de alarife que, aunque revisadas, seguirán vigentes siglos después ${ }^{26}$. Por todo ello, la participación de los mudéjares es requerida en la mayoría de las iniciativas constructivas de estos tiempos, incluso, actuando como maestros alarifes o árbitros expertos al servicio de los concejos. En muchos casos, se reconoce la labor de estos artífices, como consta, por ejemplo, en el vecino Alcázar, donde el nombre del maestre Xadel Alcalde figura en la inscripción perimetral de la sala de Solio, fechada en 1456.

Así pues, la presencia mudéjar en la construcción de la catedral de Segovia posee un peso específico en el estudio de las obras. De hecho, el primer Maestro o Veedor de Obras conocido es el mudéjar Roxo, alarife y carpintero, activo en la Catedral de 1459 a 1468:

${ }^{23}$ A.C.Sg. Libro de Fabrica, C-201. 17-X1-1464: “ En viii dias de novyenbre estando en las cuentas los señores arçedianos de Cuellar e Calatrava mandaron diesse al judio batidor del oro para la pintura de la capilla mayor myll mrs"

Libro de Fábrica C-206. 28-IV-1488: "Dy a Diego de Castro benefiçiado presentes Diego Gonsales de la Serna y Dyego de Sevylla para myll panes de oro que truxese de casa de Sornaga para los verdugos del cabildo myll e dosyentos e çinquenta mrs a dos mrs e media blanca iiMccl

Libro de Fábrica C-207. 16-VI-1488: «En dyes y seys de junio levo Diego de Sevylla y el judio Sornaga para otros myll panes otros tantos mrs iimcc"

30-VI-1488: "Compramos Diego Gonsales y Juan Alvares y yo dos myll tresyentos botones mayores e menores para dorar para poner en la obra del cabyldo de un judyo tornero a xxviii mrs el çiento que montan seisçientos quarenta y quatro"

18-V-1489: "Conpre al judio batidor tresyentos paños de oro para que labrase Rodrigo que no tenya ninguno a mrs e media blanca dclxxv"

$3^{\circ}$-VIII-1489: " En xvii de agosto truxo Jaco Anys batidor myll y dosientos y çinquenta y dos panes de oro al dicho preçio que montan dos myll y ochoçientos y dies e syete mrs porque faltaron dos panes que suma lo que pague presente Juan Alvares iimdcccxv"

${ }^{24}$ SuÁREZ, L., Documentos acerca de la expulsión de los judíos, Valladolid, 1964, pág. 208.

${ }^{25}$ Fita, F. Op. Cit., pág. 5; Baer, F., Op. Cit., pág. 520.

26 Lampérez Romea, V., La arquitectura civil española de los siglos 1-xVII, I, Madrid, 1922, pág. 214; GÓmEZ LÓPEZ, C., "LOS alarifes en los oficios de la construcción (siglos XV-XVIII)", Espacio, Tiempo y Forma, Serie VII, 4, 1991, págs. 39-52 
"16-I-1459: "Myercoles xvi de enero año de lix di al Roxo treçientos mrs que la fabrica le da en cada un año por echador e maestro de las obras de la dicha fabrica».

15-II-1460: «Dy al Roxo por maestro de las obras de la parte que cabia a la fabrica tresyentos mrs"

18-IV-1461: «En viii dias de abril pague a Juan Martines de Burgos canoygo treçientos mrs. los quales le pague por el moro Roxo por quanto el los debia al dicho Juan Martines por çierta nonada de su cassa e al dicho Roxo en salario de la yglesia"

1-IX-1461: «Pague al Roxo moro tresyentos mrs por maestro e vehedor de los hedefiçios de la yglesia"

19-Il-1463: "Di al moro Roxo de su salario tresientos mrs los quales ha por vedor de lavores e agravyos que se fase a la yglesia"

17-VIII-1464: «A el moro Roxo en salario por vedor de obras tresyentos mrs en la fabrica»

26-VIII-1465: "Al moro Roxo por beedor de las obras de la yglesia tresyentos mrs"

9-VI-1466: “Mas que dy al Roxo como beedor de las obras de su salario tresyentos"

25-VIII-1467: “Mas el Roxo de su salario tresyentos mrs»

1468: “Al Roxo de su salaryo tresyentos mrs» ${ }^{27}$.

Su función como Maestro de Obras consistía, básicamente, en cuidar del mantenimiento y conservación del templo. Esto se traduce en el control del edificio, retejados periódicos, pequeñas labores de albañilería y carpintería general con la ejecución de suelos, zaquizamies o techumbres de madera, puertas, armarios o bancos. Percibe $300 \mathrm{mrs}$ al año de la mayordomía de la Fábrica, más otros 300 que le otorgaba la de Pitanzas, veinticinco mrs. de jornal, más dos de almuerzo. Esta será la retribución habitual de todos los que luego ejercieron este cargo, ocupado, a partir de Roxo, por cristianos exclusivamente.

Si existen pocas referencias del ámbito judio, las noticias que nos han llegado respecto al colectivo mudéjar son, si cabe, más dispersas. Así, encontramos que Mahomad el Roxo es mencionado también junto con Maestre Ali de Talavera y Liaça Lobo con motivo de un requerimiento que les hace Rodrigo Mansilla, Repostero Real de Camas, mediante el corregidor de la ciudad ${ }^{28}$. También aparece en los Libros de Hipotecas y como tomador de un censo, donde se especifica que es hijo de Atimán la Partera ${ }^{29}$. En la catedral suele acompañarse de otros operarios mudéjares como son su propio hijo, Mahomad ${ }^{30}$ y Açan con los que trabaja en

27 A.C.Sg. Libro de Fabrica, C-201.

28 Archivo General de Simancas (A.G.S.). R.G.S. III-1486, f. 189. Medina del Campo, 17-III-1486. "A Sancho de Quesada, corregidor de Segovia, para que obligue a Maestre Aly de Talavera, Liaça Lobo e maestre Mahomad el Roxo, vecinos de Segovia, para que cumplan el contrato que tienen con Rodrigo de Mansilla, repostero real de camas, sobre unas obras en su casa".

29 Libro de Hipotecas de la Catedral de Segovia en Ruiz Hernando, J. A., Historia del urbanismo en la ciudad de Segovia del siglo $x /$ al $x i x$, Segovia, 1982, T.I, pág. 111. Sobre el dato de su madre cfr. VILLALPANDO, M., "Casas de Segovia entre 1464 y 1525", en Estudios Segovianos, T. XXXVII, 1996 , pág. 761 (3-III-1481).

30 Quizá este Mahoma que trabaja en la catedral pueda tratarse del alarife Mahomad de Talavera que menciona Garci Ruiz de Castro construyendo una casa para Altonso Álvarez de Villatoro en 26 de junio de 1468, vide Ruiz de CAStro, G., Comentario sobre la Primera y Segunda población de Segovia, edición de J. A. Ruiz Hernando, Segovia, 1988, pág. 44. 
las labores de carpintería, aparte de frecuentes menciones a otros sin identificar ${ }^{31}$. También se cita en el registro de obras a unos carpinteros que trabajaron en la ejecución de la sillería para el coro, realizada a principios de la década de los sesenta. Estos no son colaboradores asiduos de la catedral, sino que forman parte de la cuadrilla del maestro encargado de realizar los sitiales del nuevo coro ${ }^{32}$.

La otra actividad en la que van a sobresalir los mudéjares es en calidad de maestros enlucidores. Se ocupan de realizar las yeserías que, por otra parte, suponen uno de los factores más representativos de la construcción del cuatrocientos castellano. De todos los personajes mencionados, el único nombre que consta es el de Oseyne ${ }^{33}$. Posiblemente sea el mismo Maestre Hoçeyn que se menciona en 1476 con motivo de un arbitrio sobre unas casas de la ciudad ${ }^{34}$. Como se ha visto con la silleria del coro, es habitual que para labores muy especializadas se recurra a un equipo de artífices procedentes de otros lugares. Por ejemplo, para hacer la tribuna del reloj, que ajustara Duarte, se contrata a cuatro maestros procedentes de Valladolid que serán despedidos al concluir el trabajo ${ }^{35}$.

Existen más referencias puntuales a mudéjares, sobre todo, como proveedores de diversos productos. En 1488, se menciona a un Osmyn, maestro tornero, que vende a la iglesia piezas para hacer el artesonado de un pasillo próximo a las dependencias capitulares:

31 Estos trabajos quedan registrados en A.C.Sg. Libro de Fábrica, C-201. Ante la profusión de referencias, valgan como ejemplo las siguientes anotaciones:

3-IV-1459: "Martes iii dyas de abril año de lix este dia enpeçaron a labrar los caxones para los ornamentos e andubieron tress maestros e al Roxo e Myguell e Mahomat cada uno a veynte e çinco mrs. e al Roxo dos de almuerço cada dia que se monta setenta e syete mrs. e a este preçio a cada dieron myercoles e jueves e montan doçientos e treynta un mrs." Hay referencias sucesivas a lo largo del mes de abril y mayo.

25-VI-1460: “Este dya se encargaron de quitar las syllas viejas del coro e andubo el Roxo e Açan a cada uno e mas media açunbre de vino çinco blancas que son por todo çiento e quynse mrs veynte e çinco mrs. e tres mrs de pitança e quatro obreros a quinse mrs. e medio"

16-VII-1463: "En xvi de jullio andubo el Roxo a desfatar o derrotar o dessatar la capilla de San Lucas a $x \times \vee \%$

19-XI-1463: «En xix de novyenbre andubo el Roxo moro a faser las puertas nuevas de la capilla de Santa Ana a $x \times v " y$ fechas siguientes

7-III-1465: “ En vii dias del dicho mes dy al Roxo e a su fijo de quatro dias que labraron en las tablas del suelo del cabildo çiento e veynte e dos mrs al Roxo de un dia veynte e seys e al fijo de tres dias a veynte e quatro"

22-23-I-1466: “Martes e myercoles andovieron el Roxo e otro moro"

32 A.C.Sg. Libro de Fábrica, C-201. 12-IX-1463 «Di a los moros de maestre Juan el dia que acavaron las sillas del señor rey e reyna çien mrs para çapatos»

${ }_{33}$ A.C.Sg. Libro de Fábrica, C-201. 19-|II-1464: “En xix de março se començo el arco de Santa Catalina este dia andubieron dos maestros moros costaron çinquenta e çinco".

26-III-1464: "En xxvi de março andubo Oseyne a lusyr el dicho arco ovo treynta mrs»

34 Ruiz, A., La aljama..., págs. 33-34 (9-IV-1476).

35 A.C.Sg. Libro de Fábrica, C-201. 23- VI-1463: "Jueves xxiii de junyo andubieron quatro moros maestros en la tribuna del relox a xxv mrs son çien mrs

Este dia dy a los moros para almorsar a tres mrs"

18-VH-1463: “Este dia di a los moros maestros de Valladolid quatro mrs para aloxa luzidores del yesso"

21-VII-1463: "Este dia di a los maestros de Valladolid quatro mrs para aloxa» 
"Convenymos Diego Gonsales y Juan Alvarez y Alonso de Salamanca y yo con un fijo de Osmyn moro tornero para el corredor para los artesones mediante Rodrigo pintor y Andres Chico y Juan de Blasco despues que la tuvo de la muestra en su armario a (en blanco) cada una mandamosle faser dosyentas cc" ${ }^{36}$.

Un año después compran otras piezas con el mismo destino. En este caso, no se da ningún nombre pero presumiblemente se trate del mismo ${ }^{37}$. De 1474 , data una referencia a Maestre Hoxmin casado con Fátima, hija de Maestre Mahomad calderero y Doña Xanci, a propósito de unas casas en la morería, bajo la Puerta de San Martín ${ }^{38}$. Respecto a la herrería, en 1492, tras desaparecer temporalmente de la iglesia Yuçe Biton, en 1493 se encargan ciertos trabajos a un mudéjar ${ }^{39}$.

Otro aspecto usualmente vinculado a la artesanía mudéjar es lo que concierne a la manufactura de papel. Así vemos, que en 1483 se compra a Çaço una abultada cantidad de pergamino ${ }^{40}$. Por último, tampoco se puede obviar la excelente aportación de los mudéjares en materia textil. Si la hechura y confección de ropas, en esta catedral al menos, es realizada por judios, la mayor parte de los tejidos empleados proceden del ámbito mudéjar. Sedas, brocados, paños, alfombras son, en la mayor parte de los casos, producciones musulmanas ${ }^{41}$.

\section{LAS MINORIÁS EN EL PROCESO CONSTRUCTIVO}

Una vez contempladas las diferentes funciones que desempeñan judíos y mudéjares, conviene evaluar como estos se ensamblan dentro del complejo engranaje de la construcción catedralicia. En principio y según se desprende de la documentación, se puede hablar de un grado de convivencia y cooperación razonable. Las condiciones de trabajo y sueldos no presentan ninguna diferencia respecto a los mismos trabajos ejercidos por cristianos. Prueba de ello es que es un mudéjar, Roxo, el primer Maestro de Obras conocido, con una situación establecida en

${ }^{36}$ A.C.Sg. Libro de Fábrica, C-207. 6-X-1488.

37 A.C.Sg. Libro de Fábrica, C-206. 26-X-1489: "Conpre del moro que fase las puntas çinco myll y ochenta puntas para los verdugos del corredor a ocho mrs el çiento que montan quatrosyentos y seys mrs."

38 Ruiz, A., La aljama..., págs. 33 (17-IX-1474). Mahomad calderero, en 1480, recibe un salvoconducto de los Reyes Católicos para ir al reino de Granada, en EchEvarRía, A., "Las aljamas mudéjares en castelianas en el siglo $\mathrm{xv}$ : redes de poder y conflictos internos", Espacio, Tiempo y Forma, Serie III, t. 14, 2001, págs. 102-104.

39 A.C.Sg. Libro de Fábrica, C-208. 17-V-1493: “Que di por xcii libras e media de fierro que pesaron las barras de una claraboya que mando façer el señor Pero Sanches de Arevalo canonigo que dios aya a syete mis la libra que monto seysçientos e quarenta mrs e medio fiçolas un moro en xiii de mayo de xciii

Mas di al moro que fiço las susodichas barras porque las alargo que eran cortas e echo de fierro en elias tres libras e media xxxi»

40 A.C.Sg. Libro de Fábrica, C-204. 4. Semana-VII-1483: “Conpre de Çaço pergamynero para escrivyr las costumbres nuevas syete dosenas de pergamyno raspado y adereçado a contentamyento de Diego de Castro a çinco reales e medio la dosena que son imcxciiii»

41 A.C.Sg. Libro de Fábrica, C-214. IV-1508: “Conpre una alfombra morisca grande para la yglesia de la almoneda del obispo don Juan de Medina de buena memoria que me costo dos myll y tresientos çinquenta mrs iiMcccl» 
los mismos términos que la que luego disfrutarán sus sucesores en el cargo. De la misma manera, los obreros trabajan juntos, compartiendo tareas y taller sin que parezcan existir distinciones sobre su credo.

Otro de los exponentes más claros de la compatibilidad entre las distintas religiones del Libro es, sin duda, el respeto al Ramadán, ya que, en 1467, el mayordomo de la Fábrica no parece mostrar ningún inconveniente en que los mudéjares abandonen el trabajo para observar el ayuno. No obstante, el Maestro Roxo sigue trabajando:

"Lunes vi de abril e martes e myercoles e jueves e sabado andovo el dicho Roxo sin armarçon por el Ramadan a xxv e cada dia que son cxxv (...)

Lunes xi de mayo e martes e myercoles e jueves con el armarçon que salio el Ramadan son quatro dias cviii» 42

También se admiten las usuales fórmulas musulmanas de juramento. Aunque no tenga lugar en la catedral, Alicaro Adurame o Durame, carpintero, junto a otros dos cristianos, arbitra en calidad de alarife la división del antiguo Palacio de San Martín, residencia segoviana con carácter privado de Enrique IV e Isabel I, acogiéndose a los principios de su fe:

«(..) y el dicho Alicaro Durame dixo que juraba e juro a Ala que tiene por su Criador que dixo que bibia e no a de morir e a la parte de alta yba donde los moros dixo que hazian oracion e a las palabras de su Alcoran que dixo que fueron dichas por su profeta Mahoma que bien e fielmente juraba..." 43

En el mismo sentido, en 1489 , consta que en la ciudad se está lapidando a un mudéjar. Esta pena responde a la ley islámica, lo cual implica que la justicia cristiana, por lo menos en casos muy concretos, admite las sentencias de los tribunales propios de la comunidad musulmana ${ }^{44}$.

Por otro lado, judíos y mudéjares se implican en la vida catedralicia, incluso en importantes eventos de la más estricta religiosidad cristiana. Es extremadamente interesante la participación de los mudéjares en las representaciones litúrgicas, especialmente en las celebraciones de Corpus Christi ${ }^{45}$. El caso que nos ocupa se

42 A.C.Sg. Libro de Fábrica, C-201. Otro detalle del respeto a las costumbres alimentarias es que, en muchas ocasiones, se ofrece un ligero almuerzo a los operarios. Habitualmente el refrigerio consiste en algo de fruta y vino. Sin embargo, cuando se trata de mudéjares, el vino se sustituye por aloxa, una bebida a base de hidromiel con especias, siendo especialmente famosa la segoviana. Ver nota $n .^{\circ} 35$.

43 Archivo Diputación de Segovia. Sección Obras Pías, Caja 9, n. ${ }^{\circ} 67$. Traslado (s/f, s. Xvi). División de los Palacios de Rey en San Martín. En Segovia, 22-1-1499

44 A.C.Sg. Libro de Fábrica, C-206. 19-1I-1489: «Al dicho Françisco su hermano de tres dyas y medio que labro que el vyernes despues de medio dya fue a ver apedrear el moro y non labro clvii e medio

A su criado de quatro dyas que labro que non fue el viernes al apedreado cxx"

45 Se tiene constancia de la presencia de judíos y musulmanes en las procesiones y festejos del Corpus Christi en otros lugares, vide RuBio García, L., La procesión de Corpus en el siglo xv en Murcia, Murcia, 1987. págs. 85-86. Para este tipo de celebraciones, en general, LADERO QUESADA, M. A., Las fiestas en la cuitura medieval, Barcelona, 2004. Para Segovia, FlECNIAKOSKA, J. L., «Las fiestas del Corpus en Segovia (1594-1636)", Estudios Segovianos, T. VIII, 1956, págs. 141-201. 
refiere no tanto a las procesiones del Corpus, con carácter más social y urbano, como a los actos dispuestos en el interior de la catedral. Esta fiesta, católica por excelencia, es preparada, naturalmente, por cristianos pero también por judíos y mudéjares. Los primeros trabajando en los disfraces y los segundos actuando en los momos o actuaciones con personajes, danzas y música, quizá propiciado por el reconocimiento que disfrutaban como ministriles o instrumentistas. En las procesiones del Corpus de siglos posteriores, se seguirá recordando la participación mudéjar con la inclusión de personajes ataviados a la usanza morisca ${ }^{46}$.

Sin embargo, a pesar de este aparente clima de normalidad subyacen ciertas diferencias que distinguen a las minorías de los cristianos. Hemos visto que las relaciones laborales se rigen con los mismos parámetros pero no así los trabajos que desempeñan. Lo más relevante es el hecho de que sólo sean cristianos los que se dedican a la cantería. Dentro de la jerárquica organización del proceso constructivo, ocupan la cúspide los maestros canteros, únicos artífices con capacidad de decisión y mando en la obra, seguidos de sus oficiales y aprendices. En ningún caso, aparecen judíos o mudéjares entre ellos. Más bien, se deduce una clara delimitación de sus competencias a los oficios anteriormente expuestos: enlucidores, carpinteros, herreros..., aunque también influye su escasa tradición en el ámbito de la cantería. Es decir, que más que emplearse en la edificación propiamente dicha, se ocupan de aspectos con carácter más ornamental y subsidiario de la arquitectura. En cuanto a la pintura y a la escultura, la actividad de los no cristianos es nula.

Por otra parte, si atendemos a una perspectiva cronológica, se observa que el número de artífices, tanto judíos como mudéjares, fluctúa de modo significativo a lo largo de la segunda mitad del siglo Xv. Estas variaciones pueden estar relacionadas, en un contexto general, con la gestión desarrollada por Enrique IV e Isabel I, respectivamente, frente a las minorias. Durante los años correspondientes al reinado de Enrique IV, es cuando encontramos el mayor número de musulmanes trabajando en las obras del templo. La afluencia de estas personas, en la década de los sesenta, también se puede explicar por la maestría de Roxo. Parece razonable que siendo mudéjar el maestro de obras, recurra a su propia comunidad a la hora de buscar operarios. Por lo demás, los trabajos que se acometen en estos años coinciden con los oficios especialmente ejercidos por este colectivo, labores de car-

${ }^{46}$ A.C.Sg. Libro de Fábrica, C-205. 17-V-1481: "Que di a Byton herrrero por ocho pestinentes de fierro que fiso para las dichas alas de los angeles dos reales Ixii

Di e pague por çiento e treynta dos panes de plata para piritar las dichas alas a blanca cada uno sesenta e seys mrs Ixii

Dy para doradura para las dichas alas dies mrs $x$

Costaron dos dosenas de agujetas para los angeles honse mrs

Que di a los moros para ayudar a los gastos que fisieron en faser los momos e personajes e otras cosas que fisieron el dia de Corpus Xristi çinquenta reales syn otros çinquenta reales que Diego del Castillo les dio por mandado de los señores del cabildo et ansy mesmo di yo mas otros quinse reales para aloxa e para fruta e otras cosas que almorsaron que son por todos los reales que yo di e gaste de lo de la fabrica por mandado de los señores dos myll e quinse mrs allende de los çinquenta reales que dixo el dicho Diego del Castillo iiMxv» 
pintería y de yesería. Ya en el reinado de Isabel I, su presencia se va desvaneciendo progresivamente, apareciendo algún artífice de forma esporádica en torno a la fecha de 1492 y anotándose en los libros de Fábrica la última referencia en el año de $1495^{47}$.

Por el contrario, los judíos alcanzan una mayor representación en las décadas de los setenta y ochenta, desapareciendo radicalmente tras el fatídico Decreto de 1492. No trabajan en ningún aspecto constructivo, puesto que tampoco se puede hablar propiamente de una arquitectura judía, sino que su aportación se centra en la elaboración y venta de productos artesanales, como son la forja, la encuadernación o la confección de vestiduras. Sin olvidarnos, claro está, de la valiosísima importancia que tienen en la financiación de las obras.

Por último, cabe reseñar una cuestión que resulta muy significativa de la posición cristiana respecto a las otras religiones y es el modo en que se nombra en los Libros de Fábrica. La misión de estos Libros es registrar puntualmente todos los gastos derivados de las obras. Para ello, el mayordomo de turno hace breves pero exactas relaciones de todos los costes de jornales, materiales y objetos del templo. Esto permite reconstruir, en cierta medida, el proceso constructivo y las personas implicadas en él.

Normalmente, se especifica quién lleva a cabo el trabajo, empleando por lo general nombre y apellido, si son canteros o maestros, o sólo el nombre y el oficio que desempeñan, en el caso de los aprendices. Muchas veces se omiten nombres de peones o de operarios esporádicos. En cambio, cuando se refieren a mudéjares o judíos, excepto cuando se trata de los que adelantan fondos, no se les define de una forma civil, sino identitaria: primero se alude a su religión o raza y, luego, en algunos casos, se cita el nombre o el oficio: "vino un moro", "moro Roxo" o «judío vestimentero", por ejemplo. Este trato, distinto y no intencionado, revela que, tras la presunta equidad cristiana, se escuda una profunda conciencia de la diferencia que terminará imponiéndose, finalmente.

47 A.C.Sg. Libro de Fábrica C-208. 15-IX-1495: «Mas di a un moro por mandado del señor dean porque fiço los andamyos para pintar a Marisaltos tres reales en $\mathrm{xv}$ de setienbre de $\mathrm{xcv} \mathrm{xc}$ " 